\title{
WHAT LEADS UKRAINIAN UNIVERSITY STUDENTS TO USE WIKIPEDIA?
}

\author{
Nataliia Mulina \\ Sumy State University, Sumy, Ukraine \\ n.mulina@el.sumdu.edu.ua
}

\begin{abstract}
The Internet provides students with information from a great number of online sources. Wikipedia is one of the most frequently suggested by search engines and popular students' reference websites. The purpose of the research was to study students' use and attitudes of Wikipedia and to find out the patterns of Wikipedia use as an information source for academic purposes amongst different student groups in a Ukrainian university considering the language used. The results revealed that the overwhelming majority of students used Wikipedia and most of the respondents used it for academic purposes. Students were likely to value Wikipedia's being short and informative for writing assignments at the beginning of their work. However, the findings suggest that Wikipedia's usage is restricted by the coverage and completeness of the Wikipedia content in students' native language and the level of their knowledge of English. We found that students' major, year and mode of study as well as teachers' approval can also relate to their use of Wikipedia in relation to university studies.
\end{abstract}

Keywords: survey; university; students; Internet; Wikipedia.

\section{Introduction}

Despite how obvious as it is to implement modern computer and information technologies into the classroom, there are debates about using some Web-based tools and resources, e.g. Wikipedia, for academic purposes. Wikipedia defines itself as an openly editable, free-content online encyclopedia that involves wiki technology. Users can write and make changes to its articles; however, editing is restricted in limited cases. Today, being more than seventeen years old, Wikipedia comprises 40 million articles in 298 different languages, more than 5.5 million of which are in English. 5,193 articles are considered featured and 26,778good articles that are used as examples for writing or just meet a set of editorial standards respectively.

The role of Wikipedia in education has been evolving. It began by - and still is a subject of - serious concerns and cautions regarding the accuracy and scope of information as well as using Wikipedia citations in academic articles. The issue has been widely discussed in academic papers and in the press (Denning, Horning, Parnas, \& Weinstein, 2005; Young, 2006; Jaschik, 2007; Lladós, Aibar, Lerga, Meseguer, \& Minguillon, 2013; Coomer, 2013; Bould et al., 2014; Aibar, Lladós-Masllorens, Meseguer-Artola, Minguillón, \& Lerga, 2015).

Even so, gradually there appeared supportive voices. And today, assigning students to contribute to Wikipedia articles can be hardly considered a teaching innovation, having become a usual practice in many countries and languages. Rather, through Wikipedia Educational Programme and Wikimedia projects, it is perceived as a valuable writing assignment enhancing student learning in a study area (Lerga \& Aibar, 2015; Freire \& Li, 2016; Walker \& Li, 2016). Students are reported to be "more engaged in a research process to demonstrate ... [their] sufficient knowledge and skills" (Konieczny, 2014).

From the pedagogical point of view, Wikipedia is a vivid embodiment of the Web 2.0 tool and clearly explains to students how a collaborative activity works (for instance, as opposed to a cooperative one). While producing a wiki content in groups, students obviously improve their communication and interaction skills, and develop informational, digital and media literacy (Hafner et al., 2015; Walker \& Li, 2016; Dawe \& Robinson, 2017). Exposure to a new culture and netiquette in an online community can be as stressful to students as it is promising with regard to their opportunities for growth, learning and development (Brailas, Koskinas, Dafermos, \& Alexias, 2015). Eventually, teachers' attitudes to Wikipedia have become more favourable (Soules, 2015).

A number of studies explored perceptions of usefulness, use patterns, and motivation for using Wikipedia - for both teaching and learning - by different focus groups. The results of previous research show that the number of students using Wikipedia on the whole and for their academic studies can vary significantly - from approximately thirty to almost ninety percent in the American and Australian studies, respectively - whereas the scope of purposes remain practically the same (Pew Internet \& American Life Project, 2007; Lim, 2009; Head \& Eisenberg, 2010; Huang, Shi, Chen, \& Chow, 2016; Selwyn \& Gorard, 2016; Soler-Adillon, Pavlovic, \& Freixa, 2018).

The purposes of the research are to study students' use and attitudes of Wikipedia in a Ukrainian university with students mostly speaking Ukrainian and Russian (with a small part of foreign students taught in English) and to query if there is any consistent pattern. The study asks if different groups of students have the same or different attitudes about using Wikipedia for studying, as well as which language Wikipedia is 
mostly in-demand among them and why it is so. The study also provides indirect evidence of teachers' perception of Wikipedia as an academic information resource.

The aim to investigate the students' patterns of Wikipedia use as an information source for academic purposes guided the following research questions:

- How often is Wikipedia used as an information resource by different groups of students?

- What are students' motivations and patterns of using Wikipedia as an academic resource?

- How do students feel about the teachers' approval of their use of Wikipedia for academic purposes?

- How do students in a Ukrainian university use English, Ukrainian, and Russian Wikipedia contents?

\section{Method: Participants and Procedure}

The investigation was carried out by the Department of Foreign Languages with the support from the Centre for Social and Humanitarian Aspects of Regional Studies of Sumy State University. Data were collected during the spring of 2017 academic year from students at a mid-sized state university in Ukraine. The poll can be considered representative for a classic Ukrainian university due to the coverage of all departments (institutes). Study participants were undergraduate, graduate and postgraduate students.

A questionnaire was developed to survey use and attitudes using several single-answer and multipleanswer questions, open-ended questions, and Likert scale response-type questions. Most students were asked to complete a paper questionnaire. The same questionnaire using an online support tool was also available online and was answered mainly by part-time/distant students. The selected sample amongst those students who chose to respond consisted of 513 students, measured up with the proportional presentation in terms of year of study, subject area, and mode of study.

OSA computer application was used as a statistical tool which provided calculating frequencies, crosstabulations, and dependencies of particular indices through Likert-scale response-type, single-answer and multiple-answer question.

\section{Results}

The results of the survey indicate that about $99 \%$ of respondents reported using Wikipedia and only nearly one per cent stated they did not use it at all. Of those students using Wikipedia, more than $46 \%$ used it often, 29.24\% used it once a week, whereas almost each fourth student (23.58\%) used it even more rarely.

Table 1 shows the engagement of respondents in Wikipedia use according to varied characteristics. As can be seen, there are no simple patterns found. The use of Wikipedia was not found to strongly differ according to the years or modes of study, although we can trace a little increase in the number of those using Wikipedia less frequently from year to year. Then, more than a third of undergraduate students in their first, second and third year address Wikipedia at least once every two days.

Table 1

Frequency of students' use of Wikipedia by respondent characteristics (\%)

\begin{tabular}{|c|c|c|c|c|c|}
\hline & $\begin{array}{c}\text { Several } \\
\text { times a day }\end{array}$ & $\begin{array}{c}\text { Once } \\
\text { every } \\
\text { two days }\end{array}$ & $\begin{array}{c}\text { Once a } \\
\text { week }\end{array}$ & Seldom & Never \\
\hline \multicolumn{6}{|l|}{ Year of study } \\
\hline \multicolumn{6}{|l|}{ Undergraduate students } \\
\hline First & 17.6 & 36.0 & 26.5 & 19.9 & 0.0 \\
\hline Second & 13.3 & 32.0 & 33.6 & 19.5 & 1.6 \\
\hline Third & 9.3 & 37.4 & 26.2 & 26.2 & 0.9 \\
\hline Fourth & 16.4 & 23.9 & 28.4 & 29.8 & 1.5 \\
\hline Graduate students & 14.5 & 20.0 & 36.4 & 29.1 & 0.0 \\
\hline Post-graduate students & 20.0 & 30.0 & 20.0 & 25.0 & 5.0 \\
\hline \multicolumn{6}{|l|}{ Subject area } \\
\hline Medicine & 20.6 & 41.2 & 20.6 & 17.5 & 0.0 \\
\hline Engineering & 9.9 & 15.5 & 40.8 & 32.4 & 1.4 \\
\hline Sciences (physics \& maths), computer science and IT & 15.1 & 40.9 & 26.8 & 15.1 & 2.1 \\
\hline Law & 18.5 & 31.5 & 25.9 & 24.1 & 0.0 \\
\hline Humanities and languages & 11.1 & 33.3 & 31.3 & 24.2 & 0.0 \\
\hline Economics, management, and business technologies & 12.1 & 24.2 & 31.3 & 30.3 & 2.0 \\
\hline
\end{tabular}


In terms of the subject of study, Wikipedia is more often used by students studying Medicine, Sciences, computers, and IT: $82.4 \%$ and $82.8 \%$ of students respectively report to use it once a week and more often. Students studying Engineering and Economics, Management, and Business Technologies were found to address Wikipedia seldom. We were somewhat surprised to find students (5 in all) who never use Wikipedia - those studying Engineering (1), Sciences, Computers, and IT (2), Economics and Management (2).

The further analysis of the data reveals the reasons students are likely to use Wikipedia as a part of their study (see Figure 1). A strong majority of the respondents find information in Wikipedia short and posit its informative nature (70.96\%). Again, they use it for the first acquaintance with an issue or a topic (46.8\%). Moreover, Wikipedia is perceived as a valuable bibliographic source, thus, $34.3 \%$ of students refer to it when they need information from many sources and search for useful references. The fact that Wikipedia saves time also tends to be one of the reasons why more than one-third of students $(34.7 \%)$ acknowledge its utility.

Differences were apparent in terms of the choices made by the students in various years of study, subject areas, and mode of study (see Table 2).

Graduate students use Wikipedia more often than others (58.2\%) looking for an introduction into a topic, whereas of post-graduate students only $35 \%$ use it in such a way. Graduate students, as well as firstyear undergraduates, also value its being short and informative ( $76.4 \%$ and $80.9 \%$ respectively). Seniors $(56.7 \%)$ and post-graduates (60\%) appeared to search for brief information less than on the average. In addition, there is a noticeable decline of those undergraduate students who find Wikipedia to save time through the years of study: $c f$. First year $-50.0 \%$; Second year $-35.1 \%$; Third year $-30.8 \%$; when Fourth year - only 19,4\%. Even so, those taking graduate and post-graduate courses are inclined to return Wikipedia its time-saver status.

Students studying Law were less likely to use Wikipedia for initial introduction into a topic (38.9\%) and as a bibliographic source (22.2\%). The latter held true for students studying Economics, Management, and Business Technologies (26.3\%) but more than $40 \%$ of those studying Engineering, Sciences, Computer Science, and IT find Wikipedia useful for reference search. Clearly, students studying Law perceive it saving time significantly less than others $(22.2 \%)$.

Table 2

Students' perception of Wikipedia utility by respondent characteristics*

\begin{tabular}{|c|c|c|c|c|}
\hline & $\begin{array}{l}\text { Wikipedia is } \\
\text { short and } \\
\text { informative }\end{array}$ & $\begin{array}{c}\text { Wikipedia } \\
\text { provides } \\
\text { introduction } \\
\text { into a topic }\end{array}$ & $\begin{array}{l}\text { Wikipedia is a } \\
\text { bibliographic } \\
\text { source }\end{array}$ & $\begin{array}{r}\text { Wikipedia } \\
\text { saves time }\end{array}$ \\
\hline \multicolumn{5}{|l|}{ Year of study } \\
\hline \multicolumn{5}{|l|}{ Undergraduate students } \\
\hline First & 80.9 & 44.9 & 40.4 & 50.0 \\
\hline Second & 68.8 & 42.5 & 31.6 & 35.1 \\
\hline Third & 69.2 & 49.5 & 27.1 & 30.8 \\
\hline Fourth & 56.7 & 47.7 & 35.8 & 19.4 \\
\hline Graduate students & 76.4 & 58.2 & 38.2 & 21.8 \\
\hline Post-graduate students & 60.0 & 35.0 & 35.0 & 35.0 \\
\hline \multicolumn{5}{|l|}{ Subject area } \\
\hline Medicine & 71.1 & 44.3 & 37.1 & 38.1 \\
\hline Engineering & 70.4 & 46.5 & 40.8 & 39.4 \\
\hline $\begin{array}{l}\text { Sciences (physics \& maths), computer science } \\
\text { and IT }\end{array}$ & 70.9 & 55.9 & 35.5 & 40.9 \\
\hline Law & 70.4 & 38.9 & 22.2 & 22.2 \\
\hline Humanities and languages & 72.7 & 49.5 & 40.4 & 31.3 \\
\hline $\begin{array}{l}\text { Economics, management, and business } \\
\text { technologies }\end{array}$ & 69.7 & 42.4 & 26.3 & 32.3 \\
\hline \multicolumn{5}{|l|}{ Mode of study } \\
\hline Full-time study & 70.7 & 45.2 & 32.6 & 34.3 \\
\hline Part-time/distance study & 75.9 & 72.4 & 62.1 & 41.4 \\
\hline
\end{tabular}

Using digital technology resources in their university study on a regular basis, part-time/distance students obviously showed higher involvement in finding benefits of Wikipedia use. Perception of Wikipedia utility is almost independent of student employment status. However, no other evident patterns were found.

Preparing the survey, we realised that teachers can significantly influence students' modes of study and ways of work with learning materials. Thus, we included a question that could help us see students' 
perception of teachers' approval of their use of Wikipedia for academic purposes. An insignificant majority of respondents $(53.02 \%)$ state teachers do not recommend (or even forbid) using Wikipedia for educational purposes. Whereas overall $46.98 \%$ of respondents feel that teachers are likely to approve of and recommend using Wikipedia in their studies.

Teachers are more likely to recommend this source to the students in their first year (52.9\%). And the result from the post-graduate students is absolutely predictable: $80 \%$ of them feel teachers' disapproval as Wikipedia is obviously poor for solving scientific problems.

Teacher's approval also varies in different departments (see Table 3). In the students' perception, Law teachers are the most cautious here, and those teaching Economics, Management, and Business Technologies are the most liberal.

Table 3

Students' perception of teachers' approval of their Wikipedia use for academic purposes by respondent characteristics (\%)

\begin{tabular}{lcc}
\hline & $\begin{array}{c}\text { Teachers are not } \\
\text { likely to } \\
\text { approve }\end{array}$ & $\begin{array}{c}\text { Teachers are } \\
\text { likely to } \\
\text { approve }\end{array}$ \\
\hline Subject area & & \\
$\quad$ Medicine & 48.6 & 51.5 \\
Engineering & 53.5 & 46.5 \\
Sciences (physics \& maths), computer science and IT & 57.0 & 43.0 \\
Law & 61.1 & 38.9 \\
Humanities and languages & 59.6 & 40.4 \\
Economics, management, and business technologies & 42.4 & 57.6 \\
\hline
\end{tabular}

Finally, we reviewed how students in a Ukrainian university use the English, Ukrainian, and Russian Wikipedia contents. We provided students with the "other" option too. Figure 1 shows general distribution of students' answers and confirms the predictable first position of the Ukrainian Wikipedia and the second - of the Russian one. The fact that English Wikipedia enjoys a strong position with more than $20 \%$ of those who use it very often $(11.1 \%)$ and often $(10.1 \%)$ is indicative. However, $54.6 \%$ of respondents address is "rarely". Other languages mentioned by students include German, French, Arabic, but not all the students named the "other" Wikipedia language used.

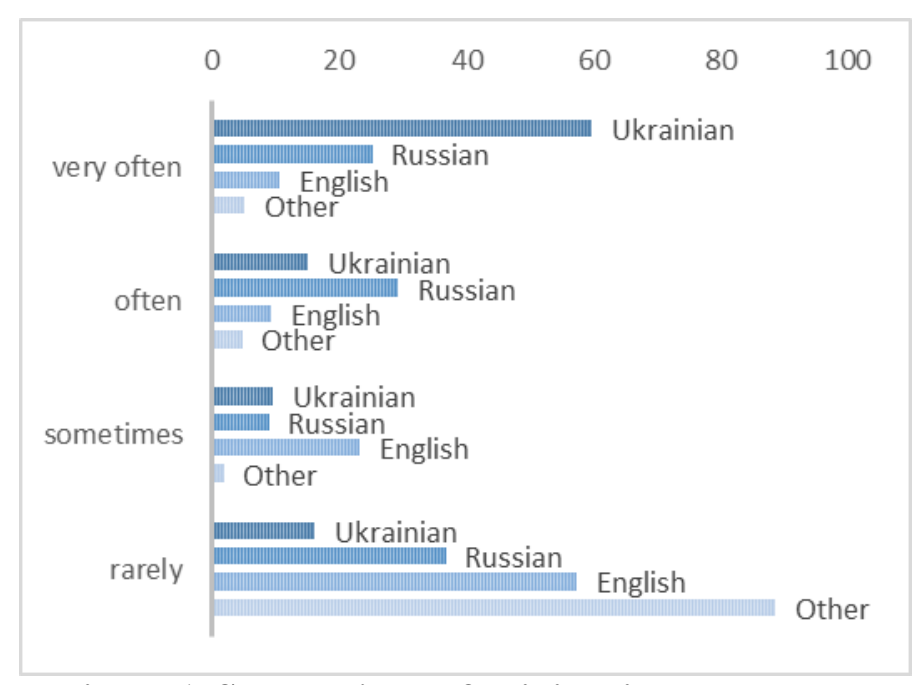

Figure 1. Students' use of Wikipedia by languages

In-depth analysis of how students use English Wikipedia contents (see Table 4) revealed that there is an uptrend for using English Wikipedia through the years of study: post-graduates naturally use it the most (overall 65\%) whereas undergraduate students in their first and second years - the least often (58.1\% and $63.3 \%$ respectively). English Wikipedia content is found to be in favour with students studying Humanities and Languages: overall $33.3 \%$ use it very often (14.1\%) and often (19.2\%). Sciences, Computer Sciences and IT is another area here with the rate higher than average (23.7\%). Engineering students need it the least (73.2\%). It is not popular amongst the students who major in Law (66.7\%) and Medicine (58.8\%). Apparently, those who use English as the language of their study prefer English Wikipedia. In this regard mode of study was found to be irrelevant. 
Table 4

Students' use of the English Wikipedia contents (\%)

\begin{tabular}{|c|c|c|c|c|}
\hline & Very often & Often & Sometimes & Rarely \\
\hline \multicolumn{5}{|l|}{ Year of study } \\
\hline \multicolumn{5}{|l|}{ Undergraduate students } \\
\hline First & 11.0 & 6.6 & 24.2 & 58.1 \\
\hline Second & 7.0 & 6.3 & 23.4 & 63.3 \\
\hline Third & 13.1 & 4.7 & 25.2 & 57.0 \\
\hline Fourth & 14.9 & 16.4 & 20.9 & 47.8 \\
\hline Graduate students & 9.1 & 18.2 & 29.1 & 43.6 \\
\hline Post-graduate students & 20.0 & 45.0 & 20.0 & 15.0 \\
\hline \multicolumn{5}{|l|}{ Subject area } \\
\hline Medicine & 10.3 & 9.3 & 21.6 & 58.8 \\
\hline Engineering & 2.8 & 2.8 & 21.1 & 73.2 \\
\hline Sciences (physics \& maths), computer science and IT & 10.8 & 12.9 & 30.1 & 46.2 \\
\hline Law & 13.0 & 5.6 & 14.8 & 66.7 \\
\hline Humanities and languages & 14.1 & 19.2 & 19.2 & 47.5 \\
\hline Economics and management, business technologies & 14.1 & 7.1 & 33.3 & 45.5 \\
\hline \multicolumn{5}{|l|}{ Mother tongue (or the language of study for foreign students) } \\
\hline Ukrainian & 10.9 & 9.4 & 26.1 & 53.6 \\
\hline Russian & 7.3 & 14.5 & 9.1 & 69.1 \\
\hline English & 44.5 & 22.2 & 22.2 & 11.1 \\
\hline
\end{tabular}

\section{Limitations}

A limitation of the survey is that the questionnaire results including open-ended students' attitudes were not sorted by gender, age or other demographics. We did not take into account students' progress in study and the context of using other resources either. This is also a comparatively small pool of 513 students and it is difficult to generalise the results on the national level - although the sample is considered representative for a middle-sized Ukrainian university.

\section{Discussion}

Most previous research studies into the problem dealt with the students speaking English and a few with other languages (Catalan, Spanish, Serbian, Croatian, Bosnian, Oriental languages). There were reported results mainly amongst college (undergraduate) students. No such a case study has been carried out in Ukraine so far.

Our research findings confirm earlier ones that Wikipedia is indeed a very popular online resource and almost all students use it. However, the deeper investigation shows that the situation is not unambiguous as far as academic purposes are concerned. The found pattern of students' access rate to Wikipedia in relation to their study (and assumed perception of Wikipedia usefulness) is not always in accord with other study reports and sometimes is counter-directional. Earlier reports noted a correlation between increased perception of Wikipedia usefulness and students' year of study (Selwyn \& Gorard, 2016). In our research, this holds partially true. The number of those who regularly use Wikipedia for undergraduate and graduate courses slightly increased, but its popularity significantly dropped with post-graduate students. Moreover, uptrends were traced amongst those who generally used Wikipedia seldom and those who used it not often for studying. What exactly underlies these findings might merit further focused research.

Students find Wikipedia's utility in saving time as well as in providing them with the initial introduction into the topic, cross-references and a sufficient bibliography. They also declare that it is short and informative. Then, positive Wikipedia perception can be credited to the fact that its information is current and presents a wide range of topics and opinions.

According to our studies, Wikipedia is more likely to help students with writing assignments at the beginning of their work. Using it for classroom discussions during seminars is less popular. This finding might be explained by the difference in terms and levels of guidance in these activities. Whereas writing assignments are mainly long-term and students are more independent in their work, classroom discussions can happen unexpectedly during interactive lectures, and seminar discussions are sometimes predetermined by a list of "recommended literature" where one can scarcely expect to find Wikipedia. Nevertheless, students reported on using Wikipedia in such a way. 
Like with other reports, Wikipedia lacks credibility: in our Ukrainian students' opinion, its information needs checking. Again, these findings testify that academics' concerns and worries about the exclusively favourable position of Wikipedia as an academic resource are grossly exaggerated.

We should not underestimate the role of a teacher in the classroom. The disproportion between the number of those who use Wikipedia in general and those who use it in their academic studies could be explained, for example, by teachers' criticism and warnings against using Wikipedia. Hence, if we know that students use Wikipedia, we should get rid of prejudice, rather guide and instruct them. Teachers need to ensure students understand how to evaluate resources and use them properly.

The results of the research displayed that the students' major is also related to the way they perceive and use Wikipedia. In our sample, students studying sciences, computers, IT, and medicine were more likely to use Wikipedia on the whole than others. It might have been because of some peculiarities of the subjects, at any rate, or the specificity of students' search requests.

Furthermore, the fact that we investigated using Wikipedia predominantly by students not speaking English clearly accounts for these results too. Students of a Ukrainian university apparently did not use English Wikipedia content in the first and second places. Remembering that coverage of the topics and completeness of information are amongst key motivators of Wikipedia usage, we can assume that the Ukrainian and Russian Wikipedia content do not meet students' needs and expectancies.

On the other hand, the English Wikipedia content is less in demand here as students' knowledge of English very often does not allow them to take advantage of its size and completeness. The results of our research confirm that students majoring in economics and management, humanities, computer sciences, and IT - these, according to our experience, with a higher level of English - use the English Wikipedia more often. Unlike other reported results (Head \& Eisenberg, 2010), students studying engineering - as our experience shows with much lower English - use the English Wikipedia the least. On the contrary, postgraduate students being obviously more advanced English language readers and speakers than undergraduate students, nevertheless their major, employ the English Wikipedia content more often for checking terms and getting familiarised with a topic. Thus, students might have used Wikipedia more often if they had known English (or another foreign language) better.

The overall impression of the research appeared to be positive for both teachers and students. In an after-survey period, some students -study participants - reported they got more interested in and more excited about Wikipedia. In addition to that, a group of IT students even suggested an algorithm of information search in course-related research using search engines and Wikipedia and presented it to their peers.

Further research about the relationship between using Wikipedia for foreign languages teaching and students' outcomes in writing assignments as well as subsequent speaking skills improvement could add to better understanding of Wikipedia use in language teaching/learning. We also aim at a deeper study of students' perception of Wikipedia usefulness regarding demographics, availability of other information resources, and through using other wiki-based collaborative projects.

\section{Conclusion}

The study explored how and why Ukrainian university students use Wikipedia on the whole and its different language content in particular. More than $75 \%$ of respondents reported having used Wikipedia in relation to their academic work and almost $25 \%$ of them do so regularly.

Students' requirement of short, informative and up-to-date content makes Wikipedia popular for finding primarily background information. It is considered to be a proper start of a course-related research and writing assignments with cross-references and bibliography available. Though, it still lacks credibility.

The use of Wikipedia and the perception of its usefulness with non-English speaking users depends, by and large, on the completeness of the Wikipedia content in their native language as well as their knowledge of both second and foreign languages. Mastery of foreign languages can do a good turn here.

Involving Wikipedia in the classroom is more challenging than fun. Faculty should concentrate on the development of students' critical thinking skills as well as incorporating Wikipedia and other Web 2.0 teaching tools into the curriculum.

\section{Acknowledgements}

We appreciate the assistance of the colleagues at the Centre for Social and Humanitarian Aspects of Regional Studies of Sumy State University. Benjamin Stewart and Dmytro Mulin made insightful comments on this paper and we thank them for their time. 
References:

Aibar, E., Lladós-Masllorens, J., Meseguer-Artola, A., Minguillón, J., \& Lerga, M. (2015). Wikipedia at university: what faculty think and do about it. The Electronic Library, 33(4), 668-683. https://doi.org/10.1108/EL-12-2013-0217

Bould, M. D., Hladkowicz, E. S., Pigford, A. A. E., Ufholz, L. A., Postonogova, T., Shin, E., \& Boet, S. (2014). References that anyone can edit: Review of Wikipedia citations in peer reviewed health science literature. BMJ (Online), 348 . https://doi.org/10.1136/bmj.g1585

Brailas, A., Koskinas, K., Dafermos, M., \& Alexias, G. (2015). Wikipedia in Education: Acculturation and learning in virtual communities. Learning, Culture and Social Interaction, 7, 59-70. https://doi.org/10.1016/j.lcsi.2015.07.002

Coomer, A. (2013). Should University Students Use Wikipedia? The Guardian, May 13, 2013. Retrieved March, 15, 2018 from https://www.theguardian.com/education/2013/may/13/should-university-students-use-wikipedia

Dawe,L., Robinson, A. (2017). Wikipedia editing and information literacy: a case study. Information and Learning Science, 118 (1/2), 5-16. https://doi.org/10.1108/ILS-09-2016-0067

Denning, P., Horning, J., Parnas, D., \& Weinstein, L. (2005). Wikipedia risks. Communications of the ACM, $48(12)$, 152. https://doi.org/10.1145/1101779.1101804

Freire, T., \& Li, J. (2016). Using Wikipedia to enhance student learning: A case study in economics. Education and Information Technologies, 21(5), 1169-1181. https://doi.org/10.1007/s10639-014-9374-0

Hafner, C. A., Chik, A., \& Jones, R. H. (2015). Guest editor commentary. Language Learning \& Technology, 19(3), 1-7. http://dx.doi.org/10125/44426

Head, A. J., \& Eisenberg, M. B. (2010). How today's college students use Wikipedia for course-related research. First Monday, 15(3). https://doi.org/10.5210/fm.v15i3.2830

Huang, J., Shi, S., Chen, Y., \& Chow, W. S. (2016). How do students trust Wikipedia? An examination across genders. Information Technology \& People, 29(4), 750-773. https://doi.org/10.1108/ITP-12-2014-0267

Jaschik, S. (2007). A stand against Wikipedia. Inside Higher Ed. Retrieved March, 15 , 2018 from http://www.insidehighered.com/print/news/2007/01/26/wiki.

Konieczny, P. (2014). Rethinking Wikipedia for the Classroom. American Sociological Association, 13, 80-84. https://doi.org/10.1177/1536504214522017

Lerga, M., Aibar, E. (2015). Best Practice Guide to Use Wikipedia in University Education. Retrieved March, 15, 2018 from https://www.researchgate.net/publication/277137842

Lim, S. (2009). How and Why Do College Students Use Wikipedia? Journal of the American Society for Information Science, 60, 2189-2202. https://doi.org/10.1002/asi.21142

Lladós, J., Aibar, E., Lerga, M., Meseguer, A., \& Minguillon, J. (2013). An empirical study on faculty perceptions and teaching practices of wikipedia. Proceedings of the European Conference on E-Learning, ECEL, 258-265. Retrieved March, 15, 2018 http://hdl.handle.net/10609/24761

Pew Internet \& American Life Project (2007). How students use Wikipedia. Retrieved March, 15 , 2018 from http://www.pewinternet. org/2007/04/24/wikipedia-users/

Selwyn, N., \& Gorard, S. (2016). Students' use of Wikipedia as an academic resource - Patterns of use and perceptions of usefulness. Internet and Higher Education, 28, 28-34. https://doi.org/10.1016/j.iheduc.2015.08.004

Shen, X. L., Cheung, C. M. K., \& Lee, M. K. O. (2013). What leads students to adopt information from Wikipedia? An empirical investigation into the role of trust and information usefulness. British Journal of Educational Technology, 44(3), 502-517. https://doi.org/10.1111/j.1467-8535.2012.01335.x

Soler-Adillon, J., Pavlovic, D., Freixa, P. (2018). Wikipedia in higher education: Changes in perceived value through content contribution. Comunicar, 54, 39-48. https://doi.org/10.3916/C54-2018-04

Soules, A. (2015). Faculty perception of Wikipedia in the California State University System. New Library World, 116(3/4), 213226. https://doi.org/10.1108/NLW-08-2014-0096

Walker, M. A., \& Li, Y. (2016). Improving Information Literacy Skills through Learning to Use and Edit Wikipedia: A Chemistry Perspective. Journal of Chemical Education, 93(3), 509-515. https://doi.org/10.1021/acs.jchemed.5b00525

Young, J. (June 12, 2006). Wikipedia Founder Discourages Academic Use of His Creation. The Chronicle of Higher Education. Retrieved from https://www.chronicle.com/blogs/wiredcampus/wikipedia-founder-discourages-academic-use-of-his-creation/2305 